\title{
Pre-laying vocal activity as a signal of male and nest stand quality in goshawks
}

\author{
V. Penteriani ${ }^{1,4}$, B. Faivre ${ }^{2}$, J. Mazuc ${ }^{3}$ and F. Cezilly ${ }^{2}$ \\ ${ }^{1}$ Department of Applied Biology, Estación Biológica de Doñana, Avda. de María Luisa \\ s/n, Pabellón del Perú, Apdo. 1056, 41013 Sevilla, Spain \\ ${ }^{2}$ Université de Bourgogne, UMR CNRS 5561 BioGéoSciences, Equipe Ecologie Evolu- \\ tive, 6 Bd Gabriel, 21000 Dijon, France \\ ${ }^{3}$ Laboratoire d'Ecologie, CNRS UMR 7625, Université Pierre et Marie Curie, 7 Quai \\ St. Bernard, Case 237, 75252 Paris, France
}

Received 9 March 2001, accepted 6 November 2001

In this study we examined male vocalisation patterns as a measure of individual and nest stand quality in goshawk Accipiter gentilis. We related the male call rate at dawn (considered to be part of a reproductive strategy) to breeding success and nest stand structure. We recorded the two main chattering-type calls of nine goshawks during the 3 months preceding egg-laying (January-March). Nest stand characteristics were assessed by means of six parameters of nest trees and four parameters of the forest stands within a 1-ha plot. The vocalisations varied significantly among individuals: successful breeders had longer vocalisations and began vocalising earlier than failed ones. Males that successfully reproduced also differed significantly from unsuccessful ones in nest stand characteristics. The results indicate that dawn vocal activity may be considered a honest advertisement of male quality, as well as the quality of its nest stand, expressed by breeding success. The conservation concerns we may gain about territory quality in relation to male vocal activity are also discussed.

KEY WORDS: vocalizations, male quality, territory quality, goshawk, Accipiter gentilis.

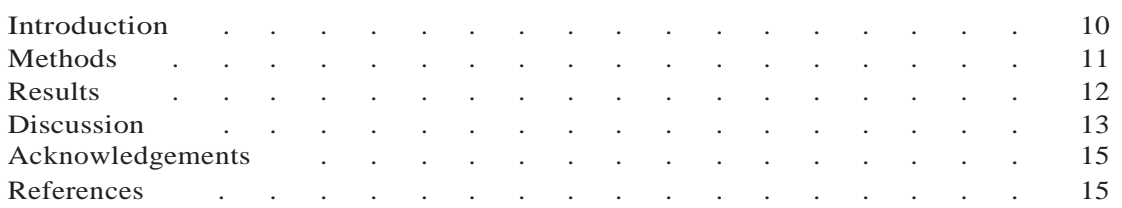

\footnotetext{
${ }^{4}$ Corresponding author: (E-mail: penteriani@ebd.csic.es).
} 


\section{INTRODUCTION}

The ecology and evolution of acoustic communication have been extensively explored and quantified in passerines (e.g. Catchpole \& Slater 1995, Kroodsma \& Miller 1996). Male vocalisations are thought to play a key role in female attraction, guarding and stimulation, and in territorial defence activities, which need not be mutually exclusive (CAtchpole \& Slater 1995). Song may therefore acts as an honest signal of male and territory quality (Hutchinson et al. 1993, Hoi-Leitner et al. 1995, Johnstone 1995). There are good theoretical reasons to believe that, in order to be reliable (honest), the signals need to be costly (ZAHAVI 1977), and singing probably involves some energetic costs (Alatalo et al. 1990, Cuthill \& MACDONALD 1990, Chappel et al. 1995, GAunt et al. 1996).

The dawn chorus, a peak of singing in the early morning performed by many passerines, is well known (MACE 1987a, Slagsvold et al. 1994, Staicer et al. 1996). If the dawn chorus is costly (e.g. it causes an expenditure of energy supplies), highquality males can spend more time singing than low-quality ones, but not vice versa (Møller 1991, Welling et al. 1995). The dawn chorus is considered to be part of paternity assurance strategies in birds (BIRKHEAD \& MøLLER 1992), and evidence of this includes its synchronisation with female fertility (e.g. MACE 1987b, Cuthill \& Macdonald 1990, Welling et al. 1995).

Information on the relationship between male quality and vocalisations are scarce for non-passerine birds. In particular, vocalisation patterns of birds of prey were rarely evaluated from an ecological and evolutionary standpoint (KLATT \& Ritchison 1994, Staicer et al. 1996, Appleby \& Redpath 1997, Galeotti 1998). In addition, studies on the reproductive behaviour of birds of prey during the early stages of the breeding season are rare (e.g. Møller 1987a, Negro et al. 1992). Finally, in the vast literature concerning birds of prey, the vocalisations of these birds are mainly regarded as an "aggressive tool" (e.g. defence of nesting territory from neighbours and/or other species), or as a mean of intra-pair communication (e.g. prey delivery by the male), and never as an element of a reproductive strategy. Mate guarding and frequent intra-pair copulations have been quantitatively described in male goshawks Accipiter gentilis, and vocalisations in this species are regarded as a strategy complementary to mate-guarding (MøLLER 1987a). Goshawk copulations are most frequent in the morning, during the egg-laying period, both before and after egg-laying (Møller 1987a, Palmer 1988, Squires \& Reynolds 1997). Early morning copulations are consistent with the paternity guarding hypothesis, and genetic data showed a low frequency of extra-pair fertilisations in goshawks (GAVIN et al. 1998). The risk of cuckoldry is considerably reduced if the two partners are close to each other during the fertile period (Davies 1985, Alatalo et al. 1987, MøLLER 1987b).

The goshawk is a socially monogamous bird of prey with a distinct dawn chorus (Penteriani 1999a, 2001). The intensity of the dawn chorus peaks in the 3 months which precede egg-laying (PENTERIANi 1999a), early April in our study area. During the dawn chorus, males are always in the proximity of the female and the nest (Penteriani 1999a, 2001). As all our study-birds were already mated, their calls were not expected to be used in mate choice per se, but as a mate-guarding strategy to prevent extra-pair copulations (MøLler 1987b). Nevertheless, some sexual choice is still possible because divorce is still possible and females may regulate their investment based on male quality (Burley 1988, De Lope \& Møller 1993). 
One basic prediction is that if male signals act as viability indicators, we would expect them to be positively correlated with other fitness-related traits and highly variable in level of expression between males (Alatalo et al. 1988). In order to test whether the calling activity of male goshawks might be used as an honest advertisement of their quality, we tested whether calling activity reflected male skills, such as parental ability expressed by nesting success and features of the selected nest stand. Based on previous studies of the energy needed for vocal activity (RAdesäter et al. 1987, Reid 1987, Alatalo et al. 1990) and on models of male and female strategies of call behaviour (Hutchinson et al. 1993, Отter et al. 1997), we made the following predictions. High-quality males were expected (1) to begin call activity earlier in relation to dawn, (2) to call continuously for a longer time, especially around the egg-laying date, (3) to reproduce successfully and (4) to have better stands.

\section{METHODS}

We observed 9 neighbouring males of goshawk in about 5000 ha of beech-forested hills of the Côte d'Or (Burgundy region, France) from late Winter to late Spring 1999. The area ranges in elevation between 300 and $450 \mathrm{~m}$ above sea level. In this area, goshawk density was 6.7 pairs $/ 100 \mathrm{~km}^{2}$, and the minimum distance between neighbouring pairs averaged $3 \mathrm{~km}$ (range $=2-3.9 \mathrm{~km}, \mathrm{SD}=0.63)$ (PENTERIANi 1999b).

We evaluated vocalisation rate on the basis of two main chattering-type calls: (1) "kek...kek...kek...": loud and widely spaced calls, interpreted as an advertising- and pair contact-call, mainly in periods of territory establishment and before egg-laying (CrAmp \& SimMONS 1980, SQUIRES \& REYNOLDS 1997); and (2) “kek-kek-kek...”: a call uttered rapidly, believed to be an alarm-call (Schnell 1958, Cramp \& Simmons 1980, Squires \& Reynolds 1997) and a high excitement contact-call between partners (PEnTERIAni 2001). Male vocalisations can be recognised and differentiated from those of the female because they are feebler, of higher pitch and repeated more slowly (Palmer 1988, Kennedy \& Stahlecker 1993, Squires \& REYNOLDs 1997). To avoid possible confusion in the sex attribution of calls, a preliminary study of goshawks vocalisation was carried-out (PENTERIANi 2001), as well as several taperecordings (successively analysed from sonograms, PenteRiani unpublished data).

We recorded vocalisations during the 3 months preceding egg-laying (January to March), from $30 \mathrm{~min}$ before sunrise to $120 \mathrm{~min}$ after (the time slot of peak vocal activity of adult goshawks, Penteriani 1999a, 2001). For each male, one listening session was established around the 15th day of each month. At each site, we selected a position that did not disturb the breeding pairs (max about $100 \mathrm{~m}$ from the nest) and we recorded the calls without changing this position. Within each time slot, we recorded (1) the time of the first vocalisation (vocal activity start), and (2) the duration of the bouts, by series of single calls (e.g. kek..) or call-series (e.g. kek-kek-kek...). We measured the duration of the vocalisations with a stop-watch, counting the seconds elapsed from the start of the sound to the last call given less than $60 \mathrm{sec}$ from the previous one. We assumed one min of silence between calls or between bouts as a dividing unit of time. An isolated single call received an arbitrary value of 1 sec. Only data recorded during mornings with good weather (no rain and wind) were included in the analysis.

Nest stand characteristics were quantified by means of 6 parameters describing the nest and the nest tree (nest height, diameter at breast height, tree height, canopy volume, mean distance between the nest tree and nearest surrounding trees, aerial flight space) and by means of 4 parameters describing the forest stand (tree diameter at breast height, trees height, canopy volume and mean distance between trees). For a detailed description of the variables, see Penteriani \& Faivre (1997). The chosen parameters, the most common in the 
analysis of the goshawk nesting habitat (SquiREs \& REYNOLDS 1997), also proved to be important in the description of the goshawk nest stand structure (PEnTERIAni \& Faivre 1997, PenteRIANI et al. 2001). We measured the characteristics of the forest stand within a plot of 1 ha around the nest tree. At the nest tree and the forest stand scales, a score was calculated for each breeding pair as its coordinate on the principal axis of a PCA computed on the two plots of habitat variables.

We performed a Repeated Measures ANOVA (SOKAL \& ROHLF 1995) to compare the duration of the vocalisations among individuals and across months. Data were logtransformed to approximate normal distributions. One-tailed t-tests for matched samples were used to examine the possibility that the months nearer the initiation of incubation were significantly higher in call duration. For each month-pair, differences were tested following the sequential Bonferroni's correction for multiple comparisons (SoKAL \& RoHLF 1995). Permutation tests for two independent samples (SIEGEL \& CASTELLAN 1988) were used to compare the characteristics of successful and unsuccessful breeders. Results were considered significant at the $P=0.05$ level. All the values are reported as means $\pm \mathrm{SD}$.

\section{RESULTS}

Five out of nine pairs produced young: the productivity was $2.0 \pm 0.7$ young per successful pair (range 1-3); egg laying took place between the 1st and the 10th April.

The duration of vocalisations (Fig. 1) was significantly different among individuals $\left(\mathrm{F}_{8,16}=3.58, P=0.014\right)$ : successful breeders vocalised more than unsuccessful ones $(P=0.04)$. The duration of vocalisations did not vary significantly among months $\left(F_{2,16}=3.05, P=0.075\right)$. However, the power of the test was low $(0.50)$ in

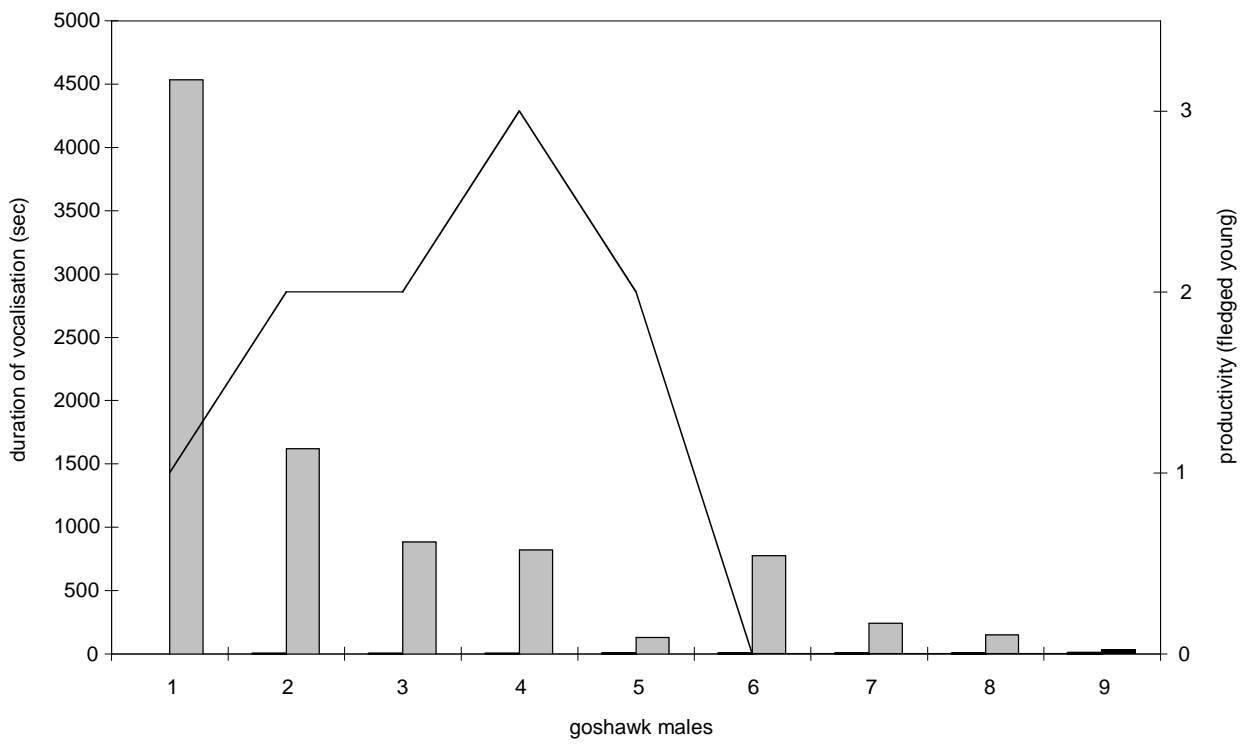

Fig. 1. - Productivity (fledged young per breeding pair; black line) and total amount of male goshawk Accipiter gentilis dawn vocal activity (sec; grey bar) in the 3 months before egg-laying (from January to March). From 1 to 5: successful males; from 6 to 9: unsuccessful males. 
Table 1.

Average nest tree and nest stand characteristics $( \pm$ SD) of successful $(n=5)$ and unsuccessful $(n=4)$ goshawk Accipiter gentilis pairs.

\begin{tabular}{lcr}
\hline Nest tree characteristics & & \\
& Successful pairs & Unsuccessful pairs \\
\cline { 2 - 3 } & & \\
Diameter at breast height $(\mathrm{m})$ & $27.2 \pm 3.11$ & $0.48 \pm 0.08$ \\
Tree height $(\mathrm{m})$ & $3786.92 \pm 622.47$ & $27.0 \pm 4.24$ \\
Canopy volume $\left(\mathrm{m}^{3}\right)$ & & $4737.65 \pm 1251.7$ \\
Distance nest tree/ & $8.14 \pm 2.54$ & $7.75 \pm 0.9$ \\
$\quad$ neighbour trees $(\mathrm{m})$ & $82.44 \pm 31.11$ & $63.24 \pm 13.87$ \\
Flight space $\left(\mathrm{m}^{3}\right)$ & $22.2 \pm 3.42$ & $17.67 \pm 2.34$ \\
Nest height $(\mathrm{m})$ & & \\
\hline Nest stand characteristics & Successful pairs & Unsuccessful pairs \\
\cline { 2 - 3 } & $0.27 \pm 0.05$ & $0.36 \pm 0.05$ \\
Diameter at breast height $(\mathrm{m})$ & $23.5 \pm 2.34$ & $21.0 \pm 3.97$ \\
Tree height $(\mathrm{m})$ & $2287.34 \pm 562.5$ & $1506.4 \pm 681.36$ \\
Canopy volume $\left(\mathrm{m}^{3}\right)$ & $6.46 \pm 0.85$ & $5.75 \pm 1.27$ \\
Tree distance $(\mathrm{m})$ & & \\
\hline
\end{tabular}

this second comparison, and we observed a trend of longer vocalisations on February $(582.8 \pm 932.7$ sec) and March $(352.7 \pm 333.7$ sec) vs January $(81.1 \pm 241.5$ sec $)$. The one-tailed t-test for matched samples indicated significant difference in call duration between March and January (sequential Bonferroni adjustment of a level, $\alpha=0.017, \mathrm{t}=-3.04, P=0.008)$, but not between February and January $(\alpha=0.025$, $\mathrm{t}=-2.11, P=0.033)$, as well as February and March $(\alpha=0.05, \mathrm{t}=0.94, P=0.813)$. March (the closer period to laying date) was the only month in which all nine goshawk males vocalised. In addition, during March, successful breeders started to vocalise earlier in the morning $(05: 48 \pm 0.01 \mathrm{hr}$; range $=05: 25-06: 18 \mathrm{hr})$ than failed ones $(06: 36 \pm 0.02 \mathrm{hr}$; range $=05: 29-07: 09 \mathrm{hr} ; P=0.008$, Permutation test).

The first axis of the PCAs explained $33.6 \%$ of the variance at the nest tree level, and $54.2 \%$ of the variance at the forest stand level. Successful individuals differed significantly from failed ones in nest stand characteristics (Permutation test for two independent samples, $P=0.008$ ), but not in nest tree characteristics. Forest stands of successful males were characterised by taller trees and a wider internal structure than unsuccessful ones, as shown by the higher values of tree height, canopy volume and tree distance (Table 1).

\section{DISCUSSION}

Goshawk vocal activity may have evolved, at least partially, in response to sexual selection (mate-guarding, MøLLER 1987b, and female physiological stimulation, CATCHPOLE \& SLATER 1995), as indicated by the particularly pronounced vocalisation rates around the female fertile period and egg-laying date (February and March). This is when the rejection of male intruders needs to be most efficient. Consequent- 
ly, aspects of vocalisations of interest to sexual selection may honestly reflect male condition, as discussed by Kroodsma \& Byers (1991). The dawn vocalisation characteristics of breeding males were associated with reproductive performance and specific nest stand characteristics. Specifically, high-quality males vocalised longer at dawn and started earlier in the morning than low-quality males, and bred in stands structurally different from those of low-quality males. Successful goshawk males spent more time singing than unsuccessful ones. As breeding success may be considered as a potential indicator of male quality, the dawn vocal activity could be considered an honest advertisement of male quality (MølLer 1991). Dawn vocal activity may represent an important cue to goshawk male quality during the period of peak female fertility, when male involvement in mate-guarding is higher (MøLLER 1987a).

MøLler (1987a) showed that call rates of male goshawks were related positively to copulation frequency. Since copulation behaviour and mate-guarding in goshawks seem to have evolved primarily in response to sperm competition (MøLLER 1987a), and a higher call rate indicates a higher copulation rate, the paternity assurance may be greater in males with high vocal activity (frequent pair copulations increase the certainty of paternity, MARTIN et al. 1974, and the last male to copulate has the highest chance of fertilising the eggs, LODGE et al. 1971).

The analysis of the vocalisation rate showed March as the only month in which all males vocalised. In our study area, 15th March represents day -20 to -25 from start of egg-laying, which is when the presence of the male near the female peaks. Therefore, all males seem to engage in mate-guarding behaviour, although at different rates, during the period which is the closest to egg-laying, while this is not the case in the other two months (although copulations between goshawks may occur during the two months before egg-laying, MøLler 1987a). During January and February, more calls were uttered by future successful males: early breeding season calling may be considered an additional signal of male quality. Since the vocalisations may also have territorial and female stimulation functions (CATCHPOLE \& SLATER 1995), high-quality males may engage in these activities earlier in the breeding season than low-quality ones. Such a pattern may be interpreted in two ways: (1) low-quality males cannot afford a high vocalisation rate over a long period (e.g. 3 months before egg-laying), but instead invest in mate guarding, which may involve lower costs (WeLLING et al. 1995); or (2) high vocal activity is associated with intensive female guarding, and low quality males do not call because they are not near the female and are often away foraging.

The ability to maintain a high song output may reflect the ability of the male to acquire the excess resources (for it and its female) that are needed to allow time for singing. This efficient acquisition of resources is probably mediated by the occupation of a high-quality territory (RADESÄTER et al. 1987, ReID 1987, Alatalo et al. 1990, Hutchinson et al. 1993, Welling et al. 1997). The interaction between individual phenotypic quality and territory quality has been demonstrated by ALATALO et al. (1985), Bollinger \& GAvin (1989) and Newton (1991). Hoi-Leitner et al. (1995) found a positive relationship between nesting site quality and song output in the blackcap Sylvia atricapilla: males who possess territories with habitat features that enhance nest site quality (e.g. vegetation cover), also sing at the highest rates, and males song rate is an indicator of male quality. Thus, song output is a strategic handicap and may honestly reflect male quality (GRAFEN 1990), as well as the quality of the territory. The time that a goshawk pair spends near the nest during the year is very long, and numerous activities require movements in the vicinity of the 
nest tree: the frequency and duration of these activities probably explains the importance of the choice of the nest stand structure. From this standpoint, male quality is reflected by the occupation of a nest stand with optimal structure. Data on breeding success also suggest that high-quality nest sites may be well hidden from predators and hold abundant food resources. In future studies, it would be important to ask if good quality males choose the best breeding habitats, or good habitats improve male quality, or if both influence the results we have observed (i.e., they are not mutually exclusive). Although the hunting territory of goshawks is not restricted to the nest stand, it may play an important role during the nestling and fledgling periods (CROCKER-BEDFord \& ChANey 1988).

Traditionally, studies on sexual selection have emphasised the quality of males, but breeding success may also depend from other factors, such as female and territory quality (CATChPole \& Slater 1995, RintAMÄKI et al. 1998). Differences in female quality may be as important as those in male quality, and should be taken into account in the context of sexual selection, as shown by RINTAMÄKI et al. (1998). Additionally, the interactions between male quality, female quality and territory quality in determining reproductive success are not easy to demonstrate and poorly understood (WOLFENBARGER 1999).

In raptors, territory quality is often related to the quality of individuals occupying it (e.g. NEwTON 1991). The interaction of these two factors strongly influences breeding output (NEWTON 1991, Sergio \& Bogliani 2000). The evaluation of individual and territory quality in species of high conservation concern like birds of prey, may represent a key element in their conservation and management. If territory quality could be reasonably and indirectly estimated by recording the call rates of its occupants, information on high quality territories could be obtained in a fast and cost-effective way during standard surveys. For this reason, we recommend further studies on the link between birds of prey vocal activity and male quality, as such a direct signal of their quality may become a powerful starting point to develop conservation and management guidelines.

\section{ACKNOWLEDGEMENTS}

We thank B.E. Arroyo, A.P. Møller, R.T. Reynolds, S.O. Rytkönen, S. Saraceni, J. Secondi, F. Sergio, J.L. Tella, J.M. Thiollay, R. Tornberg and an anonymous referee for their indepth review of the manuscript. S. Quinto (Office National des Forêts, Dijon W), provided logistic support for this work. Valduc Atomic Research Centre gave authorisation to work in its restricted area.

\section{REFERENCES}

Alatalo R.V., Glynn C. \& Lundberg A. 1990. Singing rate and female attraction in the pied flycatcher: an experiment. Animal Behaviour 39: 601-603.

Alatalo R.V., Gottlander K. \& Lundberg A. 1987. Extra-pair copulations and mate guarding in the polyterritorial pied flycatcher, Ficedula hypoleuca. Behaviour 101: 139-155.

Alatalo R.V., Höglund J. \& Lundberg A. 1988. Patterns of variation in tail ornament size in birds. Biological Journal of the Linnean Society 34: 363-374. 
Alatalo R.V., Lundberg A. \& Ulfstrand S. 1985. Habitat selection in the Pied flycatcher Ficedula hypoleuca, pp. 59-83. In: Cody M.L., Edit. Habitat selection in birds. New York: Academic Press.

Appleby B.M. \& Redpath S.M. 1997. Indicators of male quality in the hoots of Tawny Owls (Strix aluco). Journal of Raptor Research 31: 65-70.

Birkhead T.R. \& Møller A.P. 1992. Sperm competition in birds. Evolutionary causes and consequences. London: Academic Press.

Bollinger E.K. \& GAVin T.A. 1989. The effects of site quality on breeding-site fidelity in Bobolinks. Auk 106: 584-594.

Burley N. 1988. The differential-allocation hypothesis: an experimental test. The American Naturalist 132: 611-628.

Catchpole C.K. \& Slater P.J.B. 1995. Bird song. Biological themes and variations. Cambridge: Cambridge University Press.

Chappel M.A., ZuK M., KwAN T.H. \& Johnsen T.S. 1995. Energy cost of an avian vocal display: crowing in Red Junglefowl. Animal Behaviour 49: 255-257.

Cramp S. \& Simmons K.E.L. 1980. Handbook of the birds of Europe, the Middle East and North Africa. Vol. 2. Oxford: Oxford University Press.

Crocker-Bedford D.C. \& Chaney B. 1988. Characteristics of Goshawk nesting stands, pp. 210-217. In: Glinski R.L et al., Edits. Proceedings of the Southwest Raptor Management Symposium and Workshop Science and Technical Series No. 11, National Wildlife Federation, Washington, D.C.

Cuthill I.C. \& Macdonald W.A. 1990. Experimental manipulation of the dawn and dusk chorus in the blackbird Turdus merula. Behavioral Ecology and Sociobiology 26: 209-216.

DAvies N.B. 1985. Cooperation and conflict among dunnocks, Prunella modularis, in a variable mating system. Animal Behaviour 33: 628-648.

De Lope F. \& Møller A.P. 1993. Female reproductive effort depends on the degree of ornamentation of their mates. Evolution 47: 1152-1160.

Galeotti P. 1998. Correlates of hoot rate and structure in male Tawny Owls Strix aluco: implications for male rivalry and female mate choice. Journal of Avian Biology 29: 25-32.

Gaunt A.S., Bucher T.L., Gaunt S.L.L. \& Baptista L.F. 1996. Is singing costly? Auk 113: 718-721.

Gavin T.A., Reynolds R.T., Joy S.M., Leslie D. \& May B. 1998. Genetic evidence for low frequency of extra-pair fertilizations in northern goshawks. Condor 100: 556-560.

Grafen A. 1990. Biological signals as handicaps. Journal of Theoretical Biology 144: 517-546.

Hoi-Leitner M., Nechtelberger H. \& Hoy H. 1995. Song rate as a signal for nest site quality in blackcaps (Sylvia atricapilla). Behavioral Ecology and Sociobiology 37: 399-405. HutCHINSON J.M.C., Mcnamara J.M. \& Cuthill I.C. 1993. Song, sexual selection, starvation, and strategic handicaps. Animal Behaviour 45: 1153-1177.

Johnstone R.F. 1995. Sexual selection, honest advertisement and the handicap principle: reviewing the evidence. Biological Reviews 70: 1-65.

KenNedy P.L. \& STAHLECKeR D.W. 1993. Responsiveness of nesting northern Goshawks to taped broadcasts of 3 conspecific calls. Journal of Wildlife Management 57: 249-257.

Klatt P.H. \& Ritchison G. 1994. The effect of mate removal on the vocal behavior and movement patterns of male and female Eastern Screech-Owl. Condor 96: 485-493.

Kroodsma D.E. \& Byers B.E. 1991. The function(s) of bird song. American Zoologist 31: 318-328.

Kroodsma D.E. \& Miller E.H. 1996. Ecology and evolution of acoustic communication in birds. New York, NY: Cornell University Press.

Lodge J.R., FECHHEIMER N.S. \& JAAP R.G. 1971. The relationship of in vivo sperm storage interval to fertility and embryonic survival in the chicken. Biological Reproduction 5: 252-257.

MACE R. 1987a. Why do birds sing at dawn? Ardea 75: 123-132.

MAcE R. 1987b. The dawn chorus in the Great Tit Parus major is directly related to female fertility. Nature 330: 745-746.

Martin P.A., Reimers T.J., Lodge J.R. \& Dzuik P.J. 1974. The effects of ratios and numbers of spermatozoa mixed from two males on the proportion of offspring. Journal of Reproduction Fertility 39: 251-258. 
Møller A.P. 1987a. Copulation behavior in the goshawk Accipiter gentilis. Animal Behaviour 35: $755-763$

Møller A.P. 1987b. Extent and duration of mate guarding in the swallow Hirundo rustica. Ornis Scandinavica 18: 95-100.

MølLer A.P. 1991. Why mated songbirds sing so much: mate guarding and male announcement of mate fertility status. The American Naturalist 138: 994-1014.

Negro J.J., Donazar J.A. \& Hiraldo F. 1992. Copulatory behaviour in a colony of lesser kestrels: sperm competition and mixed reproductive strategies. Animal Behaviour 43: 921-930.

Newton I. 1991. Habitat variation and population regulation in Sparrowhawks. Ibis 133 (Supplement 1): 76-88.

Otter K., Chruszcz B. \& Ratcliffe L. 1997. Honest advertisement and song output during the dawn chorus of black-capped chickadees. Behavioral Ecology 8: 167-173.

Palmer R.S. 1988. Handbook of north American birds. Vol. 4. Diurnal raptors (Part I). Yale: Yale University Press.

Penteriani V. 1999a. Dawn and morning goshawk courtship vocalisations as a method for detecting nest sites. Journal of Wildlife Management 63: 511-516.

Penteriani V. 1999b. Echelles et facteurs de la sélection de l'habitat de nidification: le cas de l'Autour des palombes Accipiter gentilis. Ph.D. Dissertation, Dijon: University of Burgundy.

Penteriani V. 2001. The annual and diel cycles of goshawk vocalizations at the nest sites. Journal of Raptor Research 35: 24-30.

Penteriani V. \& Faivre B. 1997. Breeding density and nest site selection in a Goshawk Accipiter gentilis population of the Central Apennines (Abruzzo, Italy). Bird Study 44: 136-145.

Penteriani V., Frochot B. \& Faivre B. 2001. An approach to identify factors and levels of nesting habitat selection: a cross-scale analysis of Goshawk preferences. Ornis Fennica 78: 159-167.

Radesäter T., Jakobsson S., Andbjer N., Bylin A. \& Nyström K. 1987. Song rate and pair formation in the willow warbler, Phylloscopus trichilus. Animal Behaviour 35: 1645-1651.

REID M.L. 1987. Costliness and reliability in the singing behavior of ipswich sparrows. Animal Behaviour 35: 1735-1743.

RintamäKi P.T., Lundberg A., Alatalo R.V. \& Höglund J. 1998. Assortative mating and female clutch investment in black grouse. Animal Behaviour 56: 1399-1403.

SCHNELl J.H. 1958. Nesting behavior and food habits of Goshawks in the Sierra Nevada of California. Condor 60: 377-403.

Sergio F. \& Bogliani G. 2000. Eurasian Hobby density, nest area occupancy, diet, and productivity in relation to intensive agriculture. Condor 101: 806-817.

Siegel S. \& CASTEllan N.J. JR 1988. Nonparametric statistics for the behavioral Sciences, 2nd Ed. New York, NY: McGraw-Hill.

Slagsvold T., Dale S. \& Sætre G.-P. 1994. Dawn singing in the great tit (Parus major): mate attraction, mate guarding, or territorial defence? Behaviour 131: 115-138.

SoKal R.R. \& Rohlf F.J. 1995. Biometry, 3rd Ed. New York: Freeman.

Squires J.R. \& REYNolds R.T. 1997. Northern Goshawk (Accipiter gentilis). In: Poole A. \& Gill F., Edits. The birds of north America No. 298. The Academy of Natural Sciences, Philadelphia, PA, and The American Ornithologists'Union, Washington, DC.

Staicer C.A., Spector D.A. \& Horn A.G. 1996. The dawn chorus and other diel patterns in acoustic signalling, pp. 426-453. In: Kroodsma D.E. \& Miller E.H., Edits. Ecology and evolution of acoustic communication in birds. New York, NY: Cornell University Press.

Welling P.P., Koivula K.T. \& LAHTi K. 1995. The dawn chorus is linked with female fertility in the Willow Tit Parus montanus. Journal of Avian Biology 26: 241-246.

Welling P.P., RytKönen S.O., Koivula K.T. \& Orell M.I. 1997. Song rate correlates with paternal care and survival in willow tits: advertisement of male quality? Behaviour 134: 891-904.

Wolfenbarger L.L. 1999. Red coloration of male northern cardinals correlates with mate quality and territory quality. Behavioral Ecology 10: 80-90.

ZahAVI A. 1977. Reliability in communication systems and the evolution of altruism, pp. 253259. In: Stonehouse B. \&. Perrins C., Edits. Evolutionary ecology. London: Macmillan Press Ltd. 